\title{
Pengaruh Lubang Pada Kolom Akibat Gaya Aksial Tekan
}

\author{
Samsuardi BATUBARA ${ }^{1 \cdot}$ Danastasia MANIK $^{2}$
}

\begin{abstract}
This research aims to investigate the effect of hole in reinforced concrete on column capacity, particularly in carrying axial forces. Tests were performed by applying axial forces on two types of sample: with-hole and without-hole. The ultimate load obtained from both type of samples was compared to determine the effect of the hole in the concrete specimen. Four samples were made, namely: no-hole in sample; hole sized 1" (2.25\% of sample gross weight); sized 11/4" (3.52\%); sized $11 / 2 "(5.067 \%)$. The dimension of the sample is $15 \times 15 \mathrm{~cm}$, and $150 \mathrm{~cm}$ height. These four samples are reinforced with $4 D 10$ and shear reinforcement of $\phi 6$. Testing equipment used in this research is jack hydraulic with capacity of 200 tons. Based on theoretical calculation, capacity degradation caused by hole inside a column is not significant. However, our test results show that axial capacity of the colum is significantly affected by the given hole. Sample with $3.52 \%$ of sample gross weight suffered a $20.76 \%$ degradation, and sample with $5.067 \%$ of sample gross weight suffered a $33.27 \%$ degradation.
\end{abstract}

Kata kunci: kolom, benda uji berlubang, kuat tekan aksial

\section{Pendahuluan}

Estetika sering dijadikan alasan pemasangan instalasi pipa (listrik, air hujan, dll.) dalam elemen kolom. Pemasangan instalasi pipa kadang tanpa memperhitungkan degradasi kekuatan terutama pada bangunan - bangunan ruko atau bangunan tidak tinggi. Pada SNI 032847-2002 diyatakan bahwa saluran dan pipa, bersama kaitnya, yang ditanam pada kolom tidak boleh lebih dari $4 \%$ luas penampang yang diperlukan untuk kekuatan. Mengingat pentingnya elemen kolom, maka perlu diketahui sampai sejauh mana pengaruh lubang pipa terhadap kapasitas kolom dalam memikul gaya aksial tekan yang bekerja. Agar penelitian yang dilakukan fokus pada maksud dan tujuan yang ingin dicapai maka perlu dilakukan pembatasan masalah sebagai berikut:.

a. Benda uji kolom yang digunakan ada 4 buah yakni uji kolom utuh (tanpa lubang), benda uji kolom dengan lubang 1 " $(2,25 \%)$, benda uji kolom dengan lubang 11/4" $(3,52 \%)$ dan benda uji kolom dengan lubang $1 \frac{1}{2}$ " $(5,067 \%)$ dari luas bruto benda uji kolom.

b. Dimensi benda uji kolom adalah $15 \mathrm{~cm} \times 15 \mathrm{~cm}$ dengan tinggi $150 \mathrm{~cm}$ dengan menggunakan tulangan logituginal 4f10 dan tulangan tranversal f6 - 100 di daerah tumpuan dan f6 - 150 di daerah lapangan

c. Mutu beton rencana yang digunakan adalah K175

d. Alat uji tekan yang digunakan adalah jack hidrolik kapasitas 200 ton yang diberikan secara sentris pada permukaan kolom.

Pengujian dilakukan dengan dua tahap yaitu, pengujian sampel benda uji berbentuk silinder dengan ukuran $15 \times 30 \mathrm{~cm}$ untuk mendapatkan kuat tekan karakteristik benda uji dan

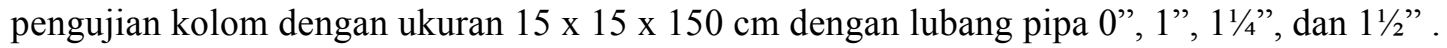

\footnotetext{
${ }^{1}$ Staf Pengajar Teknik Sipil Universitas Katolik Santo Thomas

e-mail: samsuardi_btbr@yahoo.com

${ }^{2}$ Program Studi Teknik Sipil Universitas Katolik Santo Thomas
} 


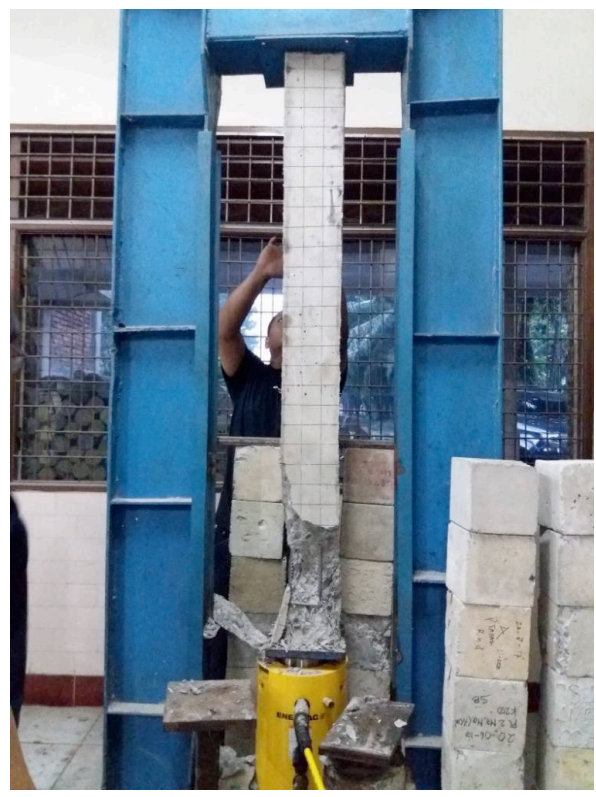

Gambar 1 Frame Compression Test

\section{Tinjauan Pustaka}

Kolom adalah batang tekan vertikal dari rangka struktur yang memikul beban dari balok, lantai dan dinding. Kolom merupakan suatu elemen struktur tekan yang memegang peranan penting dari suatu bangunan, sehingga keruntuhan pada suatu kolom merupakan lokasi kritis yang dapat menyebabkan runtuhnya (collapse) lantai yang bersangkutan dan juga runtuh total (total collapse) seluruh struktur (Sudarmoko, 1996). SK SNI T-15-1991-03 mendefinisikan kolom adalah komponen struktur bangunan yang tugas utamanya menyangga beban aksial tekan vertikal dengan bagian tinggi yang tidak ditopang paling tidak tiga kali dimensi lateral terkecil.

\section{Jenis-Jenis Keruntuhan Batasan Tekan (Kolom)}

Dari mekanika bahan telah diketahui bahwa batang tekan yang pendek dapat dibebani sampai beban meleleh dan batang tekan yang panjang akan runtuh akibat akibat tekuk elastis. Pada keadaan yang umum kehancuran akibat tekan terjadi di antara keruntuhan akibat kelelehan bahan dan akibat tekuk elastis, setelah sebagian penampang lintang meleleh, kedaaan ini diebut tekuk inelastis (inelastic buckling).

Ada tiga macam keruntuhan batang tekan, yaitu:

a) Keruntuhan akibat tegangan leleh terlampaui, hal ini terjadi pada blok tekan.

b) Keruntuhan akibat batang tertekuk elastis (elastic buckling). Keadaan ini terjadi pada bagian konstruksi yang langsing.

c) Keruntuhan akibat melelehnya sebagian serat yang disebut tekuk tak elastis (inelastic buckling). Kasus keruntuhan semacam ini beraa di antara kasus I dan kasus II. Dimana pada saat menekuk sejumlah seratnya menjadi inelastic maka modulus elastisitas ketika tertekuk lebih kecil dari harga awalnya.

Ada beberapa jenis kolom, yaitu:

a) Kolom pendek keruntuhannya akibat tegangan leleh terlampaui.

b) Kolom panjang keruntuhannya akibat batang tertekuk elastis (elastis buckling) dan akibat melelehnya sebagian serat yang disebut tekuk tak elastis (inelastic buckling). 


\section{Kolom Pendek dengan Beban Konsentris}

Telah banyak percobaan yang dilakukan dengan beban aksial namun pembebanannya dalam jangka pendek. Pada tahun 1911, Withey di University of Wisconsin mengamati bahwa dengan ditingkatnya beban di atas beban laying akan terjadi perpindahan beban dari beton ke tulangan yang artinya bahwa beton dan tulangan saling memikul beban dari beton ke tulangan, yang artinya bahwa beton dan tulangan saling memikul beban.

Di awal tahun 1930-an Komite ACI melaporkan hasil percobaan atas 546 kolom dilakukan di Lehigh University dan University of Illinois, dimana perhatian dipusatkan pada ukuran kolom, mutu beton, mutu tulangan dan jumlah tulangan memanjang dan melintang. Kecepatan pembebanan dan regangan tekan dibawah pembebanan tetap. Sejak tahun 1940 prosedur untuk perencanaan kolom dengan beban aksial didasarkan atas hasil-hasil kekuatan batas dari penyelidikan pengujian kolom tersebut.

Jika beton dan tulangan bekerjasama di dalam tekan maka perbandingan dari beban yang dipikul masing-masing, secara menerus berubah dalam pembebanan. Pada mulanya tegangan di dalam tulangan adalah Es/Ec dikali dengan tegangan beton, hal ini sesuai dengan teori elastisitas. Dengan terjadinya regangan akibat pembebanan, tulangan secara perlahan mengambil alih beban yang lebih besar. Dimana harga yang diizinkan untuk hal tersebut adalah 0,003 .

Dari rumus :

$\sigma=\frac{P}{A}$

Dengan demikian $P=\sigma \times A$

dimana :
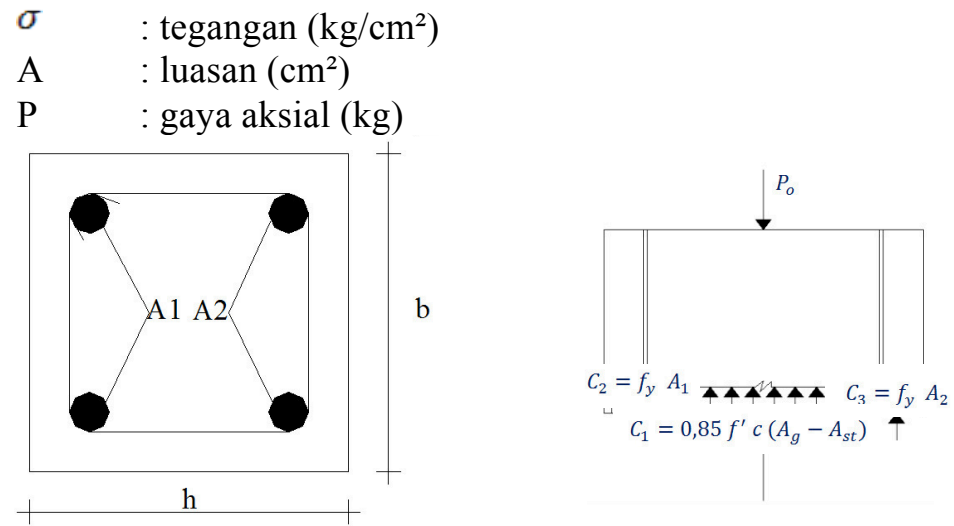

Gambar 2 Kekuatan Tekan Kolom Pendek

Hal ini juga berlaku untuk baja tulangan. Dari gambar sebelumnya dapat dirumuskan bahwa kekuatan tekan kolom pendek dengan tulangan longitudinal :

dimana,

$$
P n=0,85 f_{c}^{\prime}\left(A_{g}-A_{s t}\right)+f_{y} A_{s t}
$$

Pn : kekuatan meleleh dari kolom pendek

$f_{c} \quad:$ kekuatan beton silinder standart yang berumur 28 hari

$A_{\mathrm{g}} \quad:$ luas beton

$A_{s t} \quad$ : luas tulangan longitudinal

$f_{y} \quad$ : tegangan leleh dari tulangan memanjang 


\section{Kolom Panjang}

Analisis pada kolom panjang dibagi atas analisa terhadap dua faktor yang terjadi pada elemen tekan tersebut, yaitu : Tekuk Euler

Beban tekuk kritis untuk kolom yang ujung-ujungnya sendi disebut sebagai beban tekuk Euler, yang dinyatakan dalam Rumus Euler :

$$
P_{c r}=\frac{\pi^{2} E \cdot I}{L_{k}^{2}}
$$

Dengan rumus ini, dapat diprediksi bahwa apabila suatu kolom menjadi sangat panjang, beban yang dapat menimbulkan tekuk pada kolom menjadi semakin kecil menuju nol, dan sebaliknya. Rumus Euler ini tidak berlaku untuk kolom pendek, karena pada kolom ini yang lebih menentukan adalah tegangan hancur material. Bila panjang kolom menjadi dua kali lipat, maka kapasitas pikul beban akan berkurang menjadi seperempatnya. Dan bila panjang kolom menjadi setengah dari panjang semula, maka kapasitas pikul beban akan meningkat menjadi 4 kali. Jadi, beban tekuk kolom sangat peka terhadap perubahan panjang kolom.

\section{Hasil Pengujian}

\section{Pengujian Kuat Tekan Beton}

Pengujian benda uji beton dilakukan pada umur 28 hari dengan menggunakan Compression Testing Machine. Berikut ini dilampirkan tabel pengujian untuk sampel benda uji silinder dengan ukuran 15 x $30 \mathrm{~cm}$.

Tabel 1 Pengujian Sampel Benda Uji Silinder

\begin{tabular}{|c|c|c|c|c|c|c|c|}
\hline No & $\begin{array}{l}\text { Berat Benda } \\
\text { Uji (kg) }\end{array}$ & $\begin{array}{l}\text { Beban } \\
\text { (KN) }\end{array}$ & $\begin{array}{c}\sigma_{b} \\
\left(\mathrm{~kg} / \mathrm{cm}^{2}\right)\end{array}$ & $\begin{array}{l}\sigma_{b m} \\
\left(\mathbf{k g} / \mathbf{c m}^{2}\right)\end{array}$ & $\begin{array}{l}\left(\sigma_{b}-\sigma_{b m}\right)^{2} \\
\left(\mathbf{k g} / \mathbf{c m}^{2}\right)\end{array}$ & $\begin{array}{l}\text { SD } \\
\left(\mathrm{kg} / \mathrm{cm}^{2}\right)\end{array}$ & $\begin{array}{l}\sigma_{b k} \\
\left(\mathbf{k g} / \mathbf{c m}^{2}\right)\end{array}$ \\
\hline 1. & 12,61 & 580 & 257,778 & \multirow{8}{*}{265,833} & 64,887 & \multirow{8}{*}{42,897} & \multirow{8}{*}{197,199} \\
\hline 2. & 12,50 & 650 & 288,889 & & 531,568 & & \\
\hline 3. & 12,71 & 570 & 253,333 & & 156,256 & & \\
\hline 4. & 12,60 & 660 & 293,333 & & 756,236 & & \\
\hline 5. & 12,64 & 475 & 211,111 & & 2994,525 & & \\
\hline 6. & 12,60 & 565 & 251,111 & & 216,745 & & \\
\hline 7. & 12,53 & 650 & 288,889 & & 531,568 & & \\
\hline 8. & 12,52 & 635 & 282,222 & & 268,591 & & \\
\hline
\end{tabular}

\section{Pengujian Tarik Tulangan Baja}

Tujuan dari pengujian ini adalah untuk mengetahui besarnya tegangan leleh dan kuat tarik baja. Pengujian dilakukan di laboratorium Teknik Sipil Politeknik Medan. Benda uji yang digunakan adalah besi tulangan diameter 10 dengan mutu tulangan rata-rata fy $=350 \mathrm{MPa}$ adapun grafik hasil pengujian yang dilakukan adalah seperti gambar 3 .

\section{Perhitungan Kapasitas Kuat Tekan Kolom Secara Teoritis}

Berikut ini dilampirkan perhitungan kuat tekan kolom secara teoritis dengan berdasarkan rumus:

$P n=0,85 \times f_{c}{ }^{\prime} \times\left(A_{g}-A_{s t}\right)+f_{y} \times A_{s t}$ 


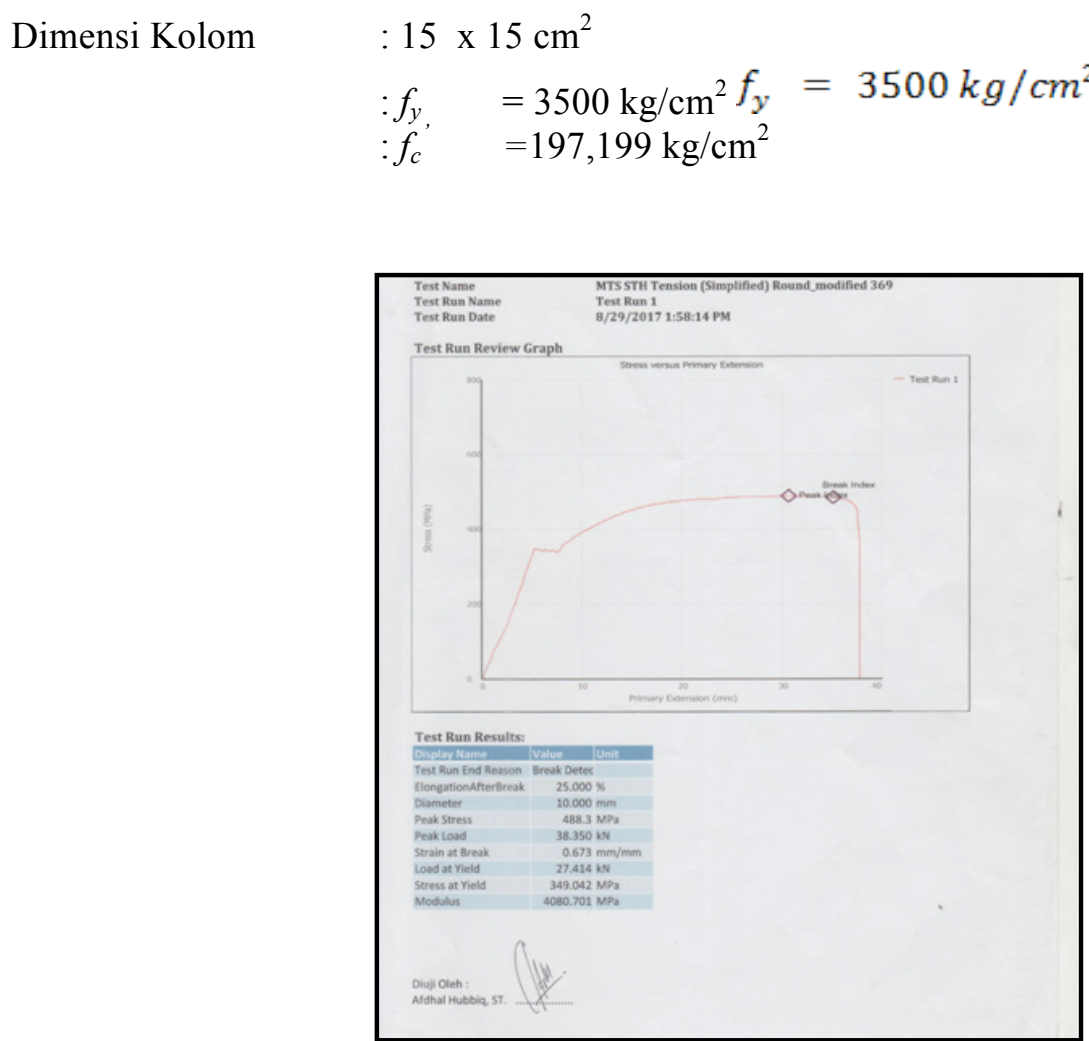

Gambar 3 Grafik Tegangan terhadap Regangan Uji Benda Uji Tulangan

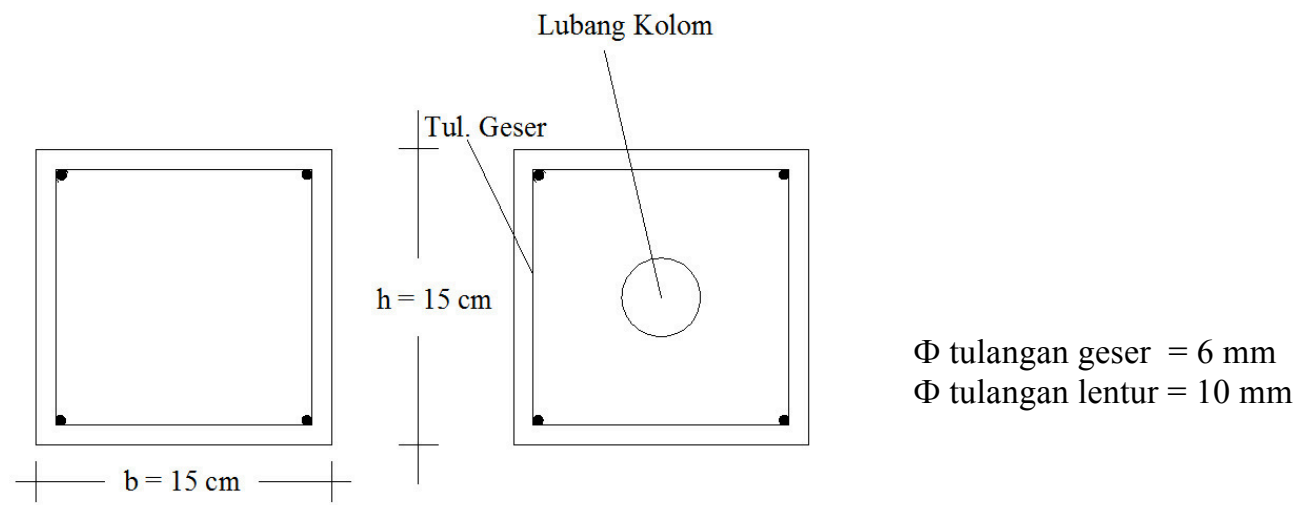

Gambar 4 Potongan Melintang Benda Uji

Tabel 2 Perhitungan Kapasitas Kolom Berdasarkan Teoritis

\begin{tabular}{|l|l|l|l|l|l|l|l|}
\hline \multirow{2}{*}{ No } & \multirow{2}{*}{ Jenis Kolom } & $\mathrm{A}_{\mathrm{g}}$ & $\mathrm{A}_{\text {lobang }}$ & $\mathrm{A}_{\mathrm{s}}$ & $\mathrm{f}^{\prime} \mathrm{c}$ & $\mathrm{f}_{\mathrm{y}}$ & $\mathrm{Pn}$ \\
\cline { 3 - 8 } & & $\left(\mathrm{cm}^{2}\right)$ & $\left(\mathrm{cm}^{2}\right)$ & $\left(\mathrm{cm}^{2}\right)$ & $\left(\mathrm{kg} / \mathrm{cm}^{2}\right)$ & $\left(\mathrm{kg} / \mathrm{cm}^{2}\right)$ & $($ ton $)$ \\
\hline 1 & Kolom Tanpa Lobang & 225 & 0 & 3.140 & 197.99 & 3500 & 48.33 \\
\hline 2 & Kolom dengan Lobang 1" & 225 & 5.067 & 3.140 & 197.99 & 3500 & 47.47 \\
\hline 3 & Kolom dengan Lobang 1 1/4" & 225 & 7.917 & 3.140 & 197.99 & 3500 & 46.99 \\
\hline 4 & Kolom dengan Lobang 1 1/4" & 225 & 11.401 & 3.140 & 197.99 & 3500 & 46.41 \\
\hline
\end{tabular}




\section{Pengujian Benda Uji Kolom}

Ada 4 (empat) buah benda uji yakni benda uji tanpa lubang, benda uji dengan lubang diameter 1" $(2,25 \%)$, benda uji kolom dengan lubang 11/4" $(3,52 \%)$ dan benda uji kolom dengan lubang 1 1/2" $(5,067 \%)$ dari luas bruto benda uji kolom. Benda uji menggunakan tulangan logituginal $4 \mathrm{f} 10$ dan tulangan tranversal $\mathrm{f} 6-100$ di daerah tumpuan dan $\mathrm{f} 6-150 \mathrm{di}$ daerah lapangan.
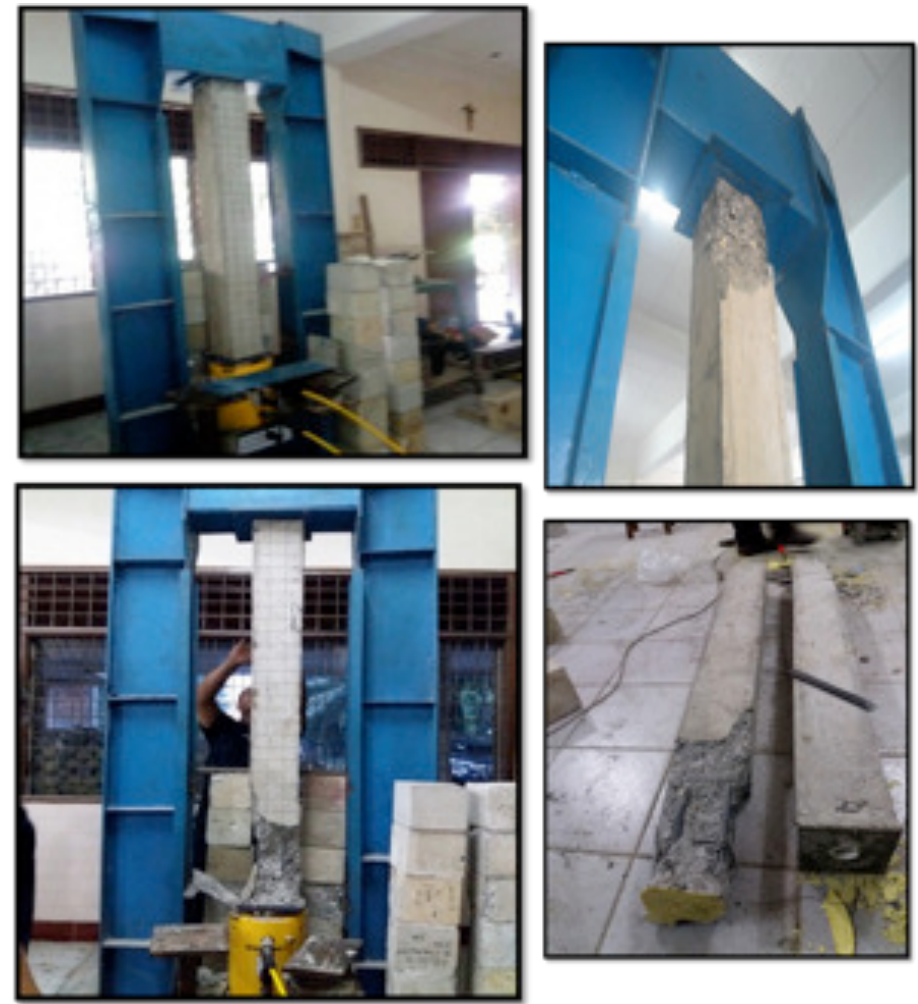

Gambar 5 Pengujian Benda Uji Kolom Tanpa Lubang \& Dengan Lubang bervariasi

Berikut dilampirkan grafik hasil pengujian kuat tekan kolom benda uji. Hasil pengujian benda uji dapat dilihat pada Grafik Kuat Tekan versus deformasi pada Gambar 6.

Berdasarkan Gambar 6. dapat diketahui bahwa benda uji kolom tanpa lubang mampu menerima beban aksial sebesar 44,884 ton dengan nilai deformasi adalah 4,03 mm, kolom dengan lubang diameter 1" mampu menerima beban aksial sebesar 43, 014 ton dengan nilai deformasi adalah 3,87 mm; kolom dengan lubang diameter $1 \frac{1}{4}$ " mampu menerima beban aksial sebesar 35,533 ton dengan nilai deformasi adalah 3,54 $\mathrm{mm}$ dan kolom dengan lubang diameter $1 \frac{1}{2}$ " mampu menerima beban sebesar 29,923 ton dengan nilai deformasi adalah $3,01 \mathrm{~mm}$. 


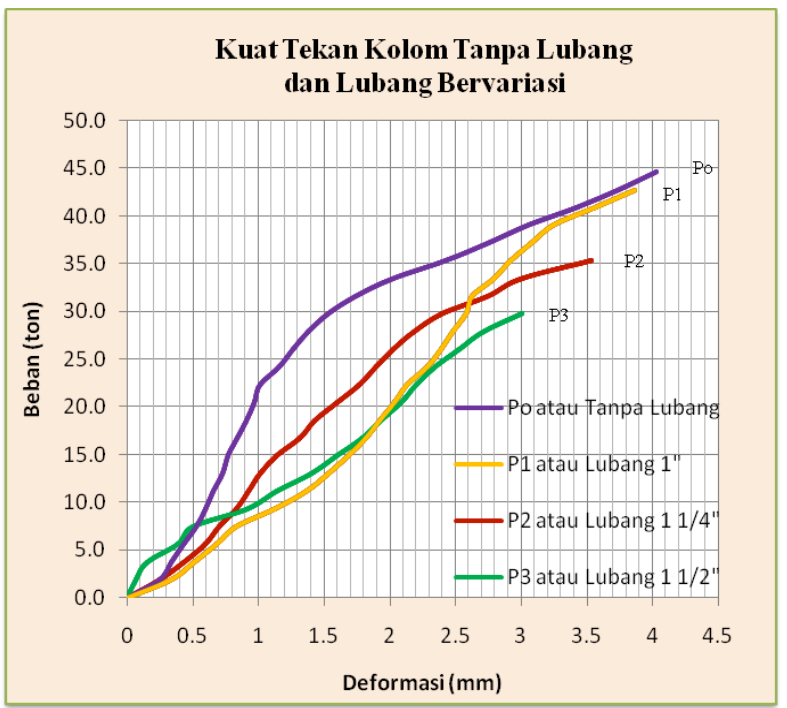

Gambar 6 Hasil PengujianKapasitas Aksial Kolom Tanpa dan Dengan Lubang Bervariasi Terhadap Deformasi

\section{Pembahasan}

Berdasarkan perhitungan secara teoritis dan pengujian diperoleh kapasitas kolom dalam memikul gaya aksial tekan seperti Tabel 3.

Tabel 3 Kuat Tekan Kolom Secara Teoritis dan Pengujian

\begin{tabular}{|l|l|l|l|}
\hline No & Diameter Lubang Kolom (inch) & P Teoritis (Ton) & P Pengujian (Ton) \\
\hline 1. & $0(0 \%)$ & 48,178 & 44,884 \\
\hline 2. & $1 ”(2,25 \%)$ & 47,439 & 43,014 \\
\hline 3. & $1 / 1 / 4 "(3,25 \%)$ & 46,851 & 35,533 \\
\hline 4. & $1 \frac{1}{2}$ " $\left.5,067 \%\right)$ & 46,267 & 29,923 \\
\hline
\end{tabular}

Dari perhitungan secara teoritis degradasi kapasitas kolom tidak signifikan sedangkan hasil analisa data pengujian degradasi kapasitas kolom cukup signifikan sementara berdasarkan hasil pengujian diperoleh kapasitas kolom dalam memikul gaya aksial seperti Tabel 4.

Tabel 4 Degradasi kapasitas kolom dalam memikul gaya tekan aksial dengan adanya lobang pada kolom

\begin{tabular}{|l|l|l|l|}
\hline No & Diameter Lubang Kolom (inch) & Pengujian (Ton) & Degradasi (\%) \\
\hline 1. & $0(0 \%)$ & 44,884 & - \\
\hline 2. & $1 ”(2,25 \%)$ & 43,014 & 04,081 \\
\hline 3. & $11 / 4 ”(3,25 \%)$ & 35,533 & 20,763 \\
\hline 4. & $1 / 2 "(5,067 \%)$ & 29,923 & 33,274 \\
\hline
\end{tabular}

Berdasarkan analisa data hasil pengujian benda uji diperoleh degradasi kapasitas kolom cukup signifikan terutama untuk kolom kolom dengan lubang 11/4" (3,25\% luas bruto benda uji) dengan degradasi kekuatan sebesar $20.76 \%$ dan untuk benda uji kolom dengan diameter lubang 11/2" (5,067\% luas bruto benda uji) degradasi kekuatan kolom dalam memikul gaya aksial tekan sebesar 33,273\%.

Berdasarkan SNI 03-2847-2002, menyatakan bahwa saluran dan pipa, bersama kaitnya, yang ditanam pada kolom tidak boleh menempati lebih dari 4\% luas penampang yang diperlukan untuk kekuatan. Bila prosentase lubang pada kolom melebihi dari 4\% akan menyebabkan 
penurunan kekuatan dari kolom yang akan mengakibatkan terjadinya keruntuhan hal tersebut sesuai dangan hasil pengujian. Berhubung luas lubang benda uji adalah 3,25\% dan5,06 \% luas bruto diperkirakan untuk lubang $4 \%$ degradasi kekuatan kolom dalam memikul aksial sekitar 30\%. Dengan degradasi kapasitas sebesar 30\% untuk lubang 4\% mungkin menjadi alasan faktor reduksi desain kolom sebesar 0,65 berdasarkan SNI 03-2847-2002 pasal 8.3 yang menyatakan bahwa saluran dan pipa, bersama kaitnya, yang ditanam pada kolom tidak boleh menempati lebih dari empat persen (4\%) luas penampang.

Dalam pelaksanaan penelitian ini, terdapat beberapa evaluasi dan masukan yang dapat dijadikan dasar dalam melakukan penelitian yang sejenis untuk meningkatkan kualitas hasil yang diperoleh, antara lain:

- Pembuatan benda uji harus benar - benar dilakukan sesuai dengan spesifikasi dan kualitas yang dinginkan.

- Benda uji harus benar - benar sempurna baik permukaan arah memanjang maupun arah melintang benda uji.

- Peralatan yang digunakan sebaiknya dilakukan secara digital dimana strain gauge ditanam didalam beton dan tulangan untuk mengetahui keruntuhan yang terjadi.

- Skema keruntuhan yang diperoleh belum sesuai yang diharapkan, dimana keruntuhan yang terjadi pada perletakan seharusnya terjadi pada tengah bentang benda uji.

- Perlu dilakukan pengujian - pengujian lanjutan dengan benda uji yang lebih banyak untuk medapatkan keakuratan hasil pengujian.

- Perlu dilakukan pengujian benda uji dengan lubang ekesentris.

\section{Kesimpulan}

Dari hasil pengujian dan analisa data yang dilakukan dapat diambil kesimpulan sebagai berikut:

- Berdasarkan analisa hasil pengujian dengan persentase luas lubang terhadap luas penampang sebesar $4 \%$ diperoleh degradasi kapasitas kolom dalam memikul aksial tekan sebesar $30 \%$.

- Pembuatan lubang untuk tujuan instalasi pipa air \& ME dalam kolom harus memenuhi SNI 03-2847-2002 pasal 8.3 yang menyatakan bahwa saluran dan pipa, bersama kaitnya, yang ditanam pada kolom tidak boleh menempati lebih dari empat persen (4\%) luas penampang.

\section{Daftar Pustaka}

Dipohusodo. (1993). Struktur Beton Bertulang Berdasarkan SKSNI T_15-1991-03. Penerbit Gramedia Pustaka Utama, Jakarta.

Neville, A. M. Properties of Concrete Third Edition. Pitman International.

Standard Nasional Indonesia. (2002). Tata Cara Perhitungan Struktur Beton Untuk Bangunan Gedung SNI $03-2847-2002$

ACI Code with Commentary $318-83$

PCA Notes on ACI 318 - 02. (2002). Building Code Requirement for Structure Concrete ( ACI 31802) and Commentary (318R-02). American Concrete Institute.

Peraturan Beton Indonesia, PBI'71 